\title{
Potential Application of Banana Peel Flour in Biofilm
}

\author{
Paloma Amancio Oliveira Sacramento ${ }^{1^{*}}$, Ingrid Lessa Leal ${ }^{1}$, Tatiana Barreto Rocha Nery ${ }^{1}$ \\ ${ }^{1}$ Integrated Center for Manufacturing and Technology, SENAI CIMATEC University Center; Salvador, Bahia, Brazil
}

\begin{abstract}
Agribusiness is a major generator of waste, which generates significant environmental impacts. However, these residues can have several applications, thus having added value. Among all fruits, the banana has the highest rate of consumption in Brazil, consequently producing large amounts of peel. This work aims to get and characterize the banana peel flour for further application in biofilm production. We performed the physicalchemical characterization of the banana peel and the flour by crushing and drying in an oven $\left(60^{\circ} \mathrm{C} / 24 \mathrm{~h}\right)$. Subsequently, we wash and delignification the pulp for its extraction. The results obtained $43 \%$ of total fiber in the flour and, at the end of the delignification process, $1.45 \mathrm{~g}$ of cellulose. Therefore, the banana peel presents itself as a potential matrix for application in the production of biofilm.
\end{abstract}

Keywords: Banana Peel. Biofilm. Banana Peel Cellulose.

Abbreviations: BPF: Banana peel flour.

\section{Introduction}

Among all fruits, banana is the most consumed in Brazil. According to IBGE data, in 2019, banana production in Brazil was approximately 7.2 million tons, and only $12 \%$ have sold as a final product [1]. We use the banana pulp for consumption and discard the peel or utilize it as organic fertilizer or in animal feed, because of the tannin content and the high amount of fiber. However, these residues can add to existing products, becoming a product with higher added value. Fruit leftovers have represented an alternative to the substitution of nonbiodegradable polymers.

Using synthetic plastics for food packaging has low-cost, high applicability, and durability. However, these materials are associated with worrying environmental impact because of their extreme resistance to degradation, requiring space for their disposal [2].

Currently, many types of packaging that protect food by the sustainable use of natural

\footnotetext{
Received on 17 June 2021; revised 18 May 2021.

Address for correspondence: Paloma Amancio Oliveira Sacramento. Av. Orlando Gomes, 1845 - Piatã, Salvador - BABrazil. Zipcode: 41650-010. Phone: (71) 3462-8449. E-mail: palomaasacramento@gmail.com.
}

J Bioeng. Tech. Appl. Health

C 2021 by SENAI CIMATEC. All rights reserved. resources are being sought through better energy use and lower waste generation. In this sense, there has been a growing development and improvement of biodegradable materials, which decompose quickly, minimizing environmental damage, since we can produce them from renewable energy sources and/or Agro-food waste from food processing industries [3].

These by-products can be used sustainably as raw material for the production of biofilm, reducing the volume of organic waste, and adding value to the chain through better use of nutrients, for example, fibers and bioactive substances with antioxidant potential, which can cooperate with the improvement of the functional characteristics of this type of packaging [4].

Usually, the films should present some characteristics for food packaging: good sensory qualities, good barrier properties, efficient mechanical properties, microbiological, physicochemical, and biochemical stability, absence of harmful components to health, simple technology, low-cost, and nonpolluting [3]. Among the materials, those of agricultural origin present an advantage for biodegradable packaging because they are available all year round, are cheaper, and come from a renewable source [2]. This work aims to get and characterize the flour from the banana peel as a potential application in preparing biofilm. 


\section{Materials and Methods}

The company BioAlimentos, Camaçari-BA, provided the samples of banana peel to our study. The experiments occurred in the bionutrition laboratory of SENAI CIMATEC.

After receiving the shells, we washed them in running water to remove surface impurities, later we sanitized them in a $10 \mathrm{ppm}$ sodium hypochlorite solution for 15 minutes. We used drinking water for rinsing. We dried the banana peels in an oven with forced air circulation (Q314M222, Chemis) at $60^{\circ} \mathrm{C}$ for 24 hours. Subsequently, we ground them in a household blender to produce the flour.

The infrared moisture balance (MOC$120 \mathrm{H}$; Shimadzu) characterized the moisture content of the banana peel flour (BPF), with the incidence of the heat of $105^{\circ} \mathrm{C}$, and the decagon (Novasina, Lab Master aw) identified the water activity [5]. The ash content was 5 to $10 \mathrm{~g}$ of the sample (capsule), previously heated in a muffle furnace at $550^{\circ} \mathrm{C}$. It was cooled in a desiccator to room temperature and weighed. We have repeated the heating and cooling operations until the weight remained constant [5].

Soxhlet extractor determined the lipid content [5]. We weighed $3 \mathrm{~g}$ of the sample in a cartridge previously prepared with filter paper and cotton, then filled the cartridge with cotton until it covered the entire sample. Then, the extractor was attached to the flat bottom flask previously stared at $105^{\circ} \mathrm{C}$. The cartridge was placed into the extractor apparatus. Then, we added enough ether for one and a half Soxhlet and connected the assembly to the condenser. We turned on the heating plate and kept it warm for a long time. Removed the assembly, taking care to remove as much ether from the flask as possible first. Transferred the flask with the extracted residue to an oven at $105^{\circ} \mathrm{C}$, holding for about an hour. Then took it to cool in the desiccator to room temperature, weighed with this process, and repeated the operations of heating for 30 minutes in the oven and cooling until the weight was constant [5].

We performed protein determination according to the Kjeldahl Method available in the literature [5]. Weighed $1 \mathrm{~g}$ of the sample on tissue paper, then transferred to the Kjeldahl flask (paper + sample). Added $25 \mathrm{~mL}$ of sulfuric acid and about $6 \mathrm{~g}$ of the catalyst blend and heated on an electric plate in the hood until the solution turned blue-green and free of undigested material (black spots). Heated for another hour and allowed to cool. Immediately connected the flask to the distillation assembly. We dipped the tapered end of the soda into $25 \mathrm{~mL}$ of $0.05 \mathrm{M}$ sulfuric acid in a $500 \mathrm{~mL}$ Erlenmeyer flask with 3 drops of the methyl red indicator; added to the flask containing the digested sample, via a funnel with a stopcock, 30\% sodium hydroxide solution to ensure a slight excess of base. We got heated to boiling and distilled until about $250 \mathrm{~mL}$. Titrated the excess $0.05 \mathrm{M}$ sulfuric acid with $0.1 \mathrm{M}$ sodium hydroxide solution using methyl red [5].

For determining the total dietary fiber content, we did appropriate pre-treatments for moisture and lipid content reduction, then measured the volume of the hydrolysate got from the enzymatic treatment. We added $95 \%$ of alcohol at $60^{\circ} \mathrm{C}$, measured after heating, in a ratio of $4: 1$ of the hydrolysate volume. Covered the beakers with aluminum foil and let the mixture stand at room temperature for 1 hour for precipitation of the soluble fiber fraction. The crucible, previously prepared and weighed, was placed in a Kitasato attached to a vacuum tube. $15 \mathrm{~mL}$ portion of $78 \%$ alcohol was passed through the crucibles to redistribute the glass wool. We filtered the alcohol solution containing the hydrolysis residue carefully to not exceed the level of the glass wool during the filtration. We washed the residue with two $15 \mathrm{~mL}$ portions of $95 \%$ alcohol and two $15 \mathrm{~mL}$ portions of acetone; dried the crucibles containing them in an oven at $105^{\circ} \mathrm{C}$ overnight. Cooled in a desiccator and weighed (P2 for the sample and B2 for the blank). After the evaluating, we determined the protein content in one crucible of the sample and one blank [5]. 
We performed the quantification of sodium and potassium ions in a flame photometer with wavelengths at 589 and $766 \mathrm{~nm}$; zeroed the measuring scale with distilled and deionized water; and after shaking the samples, we transferred about $40 \mathrm{~mL}$ to a clean, dry beaker. The photometer calibrated and zeroed red the samples [5].

For the delignification and bleaching process, $30 \mathrm{~g}$ of BPF was used and washed in $2 \%$ sodium hydroxide solution (1.2L of solution) at $80^{\circ} \mathrm{C}$ for 4 hours under stirring using a hot plate. Distilled water at room temperature filtered and washed the sample. We repeated this process 4 times to remove the water-soluble agents and get a cellulosic pulp [6]. Added $300 \mathrm{~mL}$ of buffer solution (27 $\mathrm{g}$ of solid sodium hydroxide plus $75 \mathrm{~mL}$ of acetic acid) into $25.47 \mathrm{~g}$ of the BPF, leaving for 10 minutes under constant stirring. Then we added the $1.7 \%$ sodium hypochlorite solution at $80^{\circ} \mathrm{C}$ and kept it at rest for 6 hours. Again, the distilled water filtered and washed the pulp. We dried the pulp in an oven with forced air circulation at $30^{\circ} \mathrm{C}$ for 24 hours.

\section{Results and Discussion}

After the process, the banana peel flour (BPF) became homogeneous, thin, brown, and had approximately $6.50 \%$ (Figure 1 ).

Table 1 shows the values of the physicochemical characterization of the banana peel in natura and $\mathrm{BPF}$, and mean \pm standard deviation presents the results.
The moisture contents were $83.78 \%$ for banana peel and $5.723 \%$ for banana peel flour, differing significantly from each other. However, it is within the standard required by ANVISA, a maximum of $15 \%$ moisture content in flours [7]. The water activity content was $0.857 \%$ for banana peel and $0.389 \%$ for banana peel flour, respectively. Products with water activity above 0.70 allow enzymatic or non-enzymatic reactions, and these cause modifications in the color, flavor, and stability of BPF [8].

The ash contents were $2.72 \%$ for plantain peel and $0.24 \%$ for plantain peel flour. This content is satisfactory in the banana peel, but the preparation process of the banana peel flour has a significant reduction in mineral content. However, the literature data found amounts of potassium, calcium, magnesium, zinc, among other minerals following this process [9].

The banana peel presents significant amounts of fibers, important for the production of biofilm. We can use them as additives, which help to improve their mechanical properties. These values are also important due to the intake of fiber for the human being to assist in the gastrointestinal tract, besides controlling some chronic degenerative diseases [10]. BPF also presented interesting nutritional results, such as protein and lipid content, and it can also be applied in food formulations.

For application in biofilm production, the literature suggests the reduction of the flour granulometry to improve the film appearance, obtaining a smooth texture and films of small

Table 1. Physicochemical characterization of banana peel in natura and banana peel flour (BPF).

\begin{tabular}{lcc}
\hline Test & Banana peel & BPF \\
\hline Moisture (\%) & $83.78 \pm 0.94$ & $5.723 \pm 0.06$ \\
Water activity & $0.857 \pm 0.01$ & $0.389 \pm 0.01$ \\
Ash (\%) & $2.72 \pm 0.11$ & $0.24 \pm 0.02$ \\
Lipids (\%) & $0.35 \pm 0.03$ & $10.93 \pm 0.18$ \\
Proteins (\%) & $2.37 \pm 0.36$ & $8.11 \pm 0.04$ \\
Total dietary fiber $(\%)$ & $24.49 \pm 0.25$ & $43.89 \pm 0.52$ \\
Sodium $(\mathrm{Na})(\mathrm{g} / 100 \mathrm{~g})$ & $<0.0021$ & $0.0128 \pm 0.01$ \\
Potassium $(\mathrm{K})(\mathrm{g} / 100 \mathrm{~g})$ & $0.716 \pm 0.01$ & - \\
\hline
\end{tabular}


Figure 1. Banana peel flour.

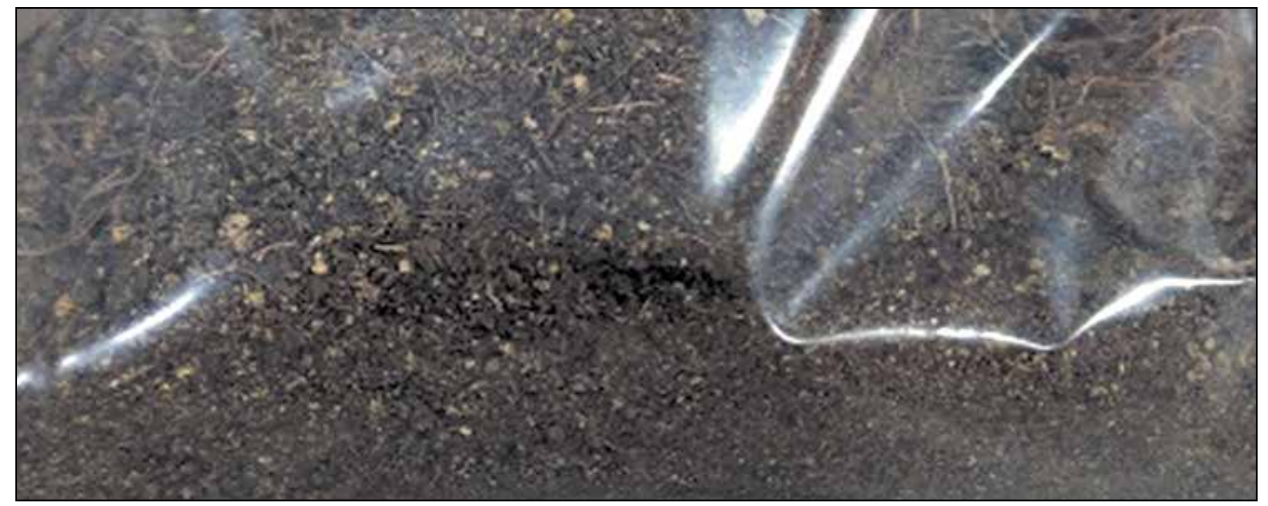

Figure 2. Banana peel flour-washing process (A: $1^{\text {st }}$ Wash; B: $2^{\text {nd }}$ Wash; C: $3^{\text {rd }}$ Wash; D: $4^{\text {th }}$ Wash).

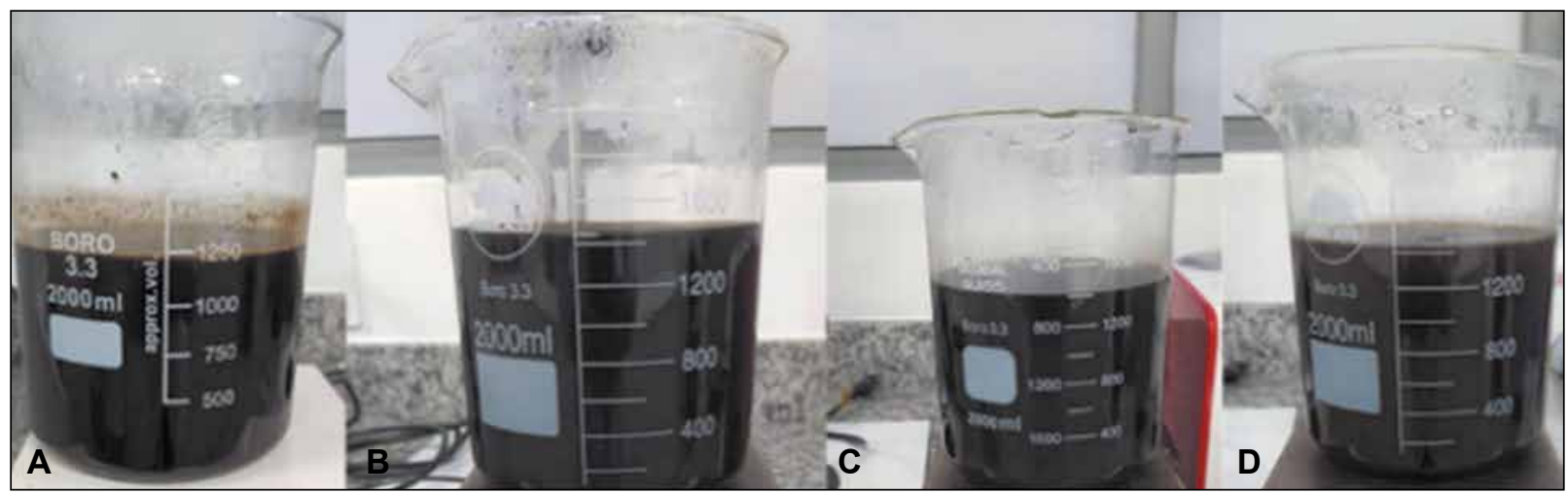

Figure 3. Delignification process (E) and obtaining pulp (F).

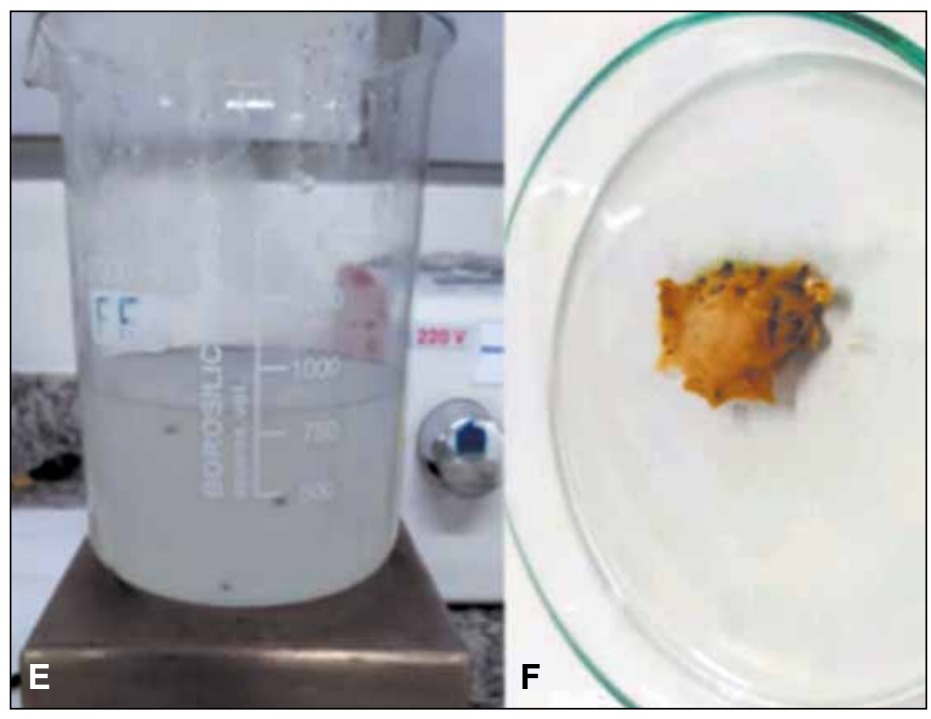


thickness. We performed the washing and bleaching phase 4 times for the complete removal of the water-soluble agents. The pulp gets lighter and lighter throughout the washes (Figure 2). We performed the bleaching to remove substances, mainly lignin, which gives a darker color to the pulp (Figure 3).

After bleaching, the BPF was ovendried [6]. $1.45 \mathrm{~g}$ of cellulose was obtained, representing a total yield of $4.83 \%$. Xavier (2018) [11] found values of $23 \%$ cellulose in Musa banana peel. Aregheore (2005) [12] reported 25\% cellulose in his work.

An important factor is the ripening stage of the fruit. The percentage of cellulose and other components vary according to the ripening stage. In this study, we used peels of ripe fruit, which may explain the low yield of cellulose because during ripening occurs the enzymatic synthesis, proper of the fruit, which causes this natural degradation. We can optimize these values by improving the extraction method. The results obtained suggest that the BPF presents itself as an interesting matrix to get reinforcement material to be applied in films. However, the laboratory tests foreseen in the work plan are under development, and later we will elaborate and characterize the films.

\section{Conclusion}

Currently, the scientific field aims at sustainability, reuse, and innovation of what we already have, thinking so, the present study uses the banana peel because this waste has possible for several purposes.

The banana peel flour presented an interesting total fiber composition for cellulose extraction for biofilm production and converted into highvalue-added materials. It can also add mechanical resistance to the material developed. Besides, it has several interesting properties to be used in food formulations. Thus, we hoped to obtain a biofilm with properties compatible with the application in the food industry.

\section{Acknowledgments}

To my advisors for their corrections and teachings. The company BioAlimentos for giving the samples and the CNPq scholarship for providing the scholarship.

\section{References}

1. IBGE. Systematic survey of agricultural production - LSPA. Rio de Janeiro: IBGE, 2020.

2. Carr LG. Development of biodegradable packaging from cassava starch. 2007. $93 \mathrm{f}$. Thesis (Doctoral) Chemical Engineering Course, Polytechnic School of the University of São Paulo, São Paulo, 2007.

3. Souza CO. Preparation, characterization, and evaluation of the effectiveness of biofilms based on cassava starch (Manihot esculenta crantz) and incorporated with mango (Mangifera indica $l$ ) and acerola (Malpighia emarginata $l$ ) pulps as antioxidant additives. 2010. $143 \mathrm{f}$.

4. Debeaufort F, Quezada-Gallo JA, Voilley A. Edible films and coatings: tomato packaging: A review. Crit. Rev. Food Sci. 1998;(38)4:299-313.

5. São Paulo. Odair Zenebon. Secretary of State of Health. Physical-chemical methods for food analysis. 4. ed. São Paulo: Adolfo Lutz Institute, 2008. 1000 p.

6. Machado BAS, et al. Obtaining nanocellulose from green coconut fiber and incorporation into biodegradable starch films plasticized with glycerol. Chem. Nova [online]. 2014;37(8):1275-1282. ISSN 0100-4042.

7. Anvisa. Agência Nacional de Vigilância Sanitária. Resolution - CNNPA No. 12, 1978.

8. Pessoa TRB, et al. Avaliação do processo de obtenção de farinha de pele de banana (Musa sapientum) das variedades Prata, Pacovan e Apple. 2009.

9. Gondim JA, et al. Centesimal and mineral composition of fruit peels. Ciência e Tecnologia de Alimentos 2005;(25)4:825-827.

10. Catalani LA, et al. Dietary fiber. Revista Brasileira de Nutrição Clínica. São Paulo: Brazilian Society of Parenteral and Enteral Nutrition 2003:178-182.

11. Xavier LS. Extraction of cellulose from peeled silver banana (M. ssp) by a green method and evaluation of the influence of water on the molecular structure of cellulose. 2018:89.

12. In Aregheore. Evaluation and use of noni (Morinda citrifolia) juice residue in complete goat diets. Analysis 2005;90(88.3):92-6. 